Proceedings of the

International Geometry Center

Vol. 10, no. 1 (2017) pp. 47-58

\title{
Потоки Морса-Смейла на торі $з$ діркою
}

\author{
Пришляк О. О., Прус А. А.
}

\begin{abstract}
In this work we consider Morse-Smale flows on torus with hole whose singularities lie on the boundary of this surface. A complete topological invariant for such flows is constructed and total number of topologically nonequivalent flows on this surface with 4,6 , and 8 singular points is calculated. We also obtain a topological classification of these flows and describe their topological structure.

Анотація. У даній роботі розглядаються потоки Морса-Смейла на торі з діркою, особливі точки яких лежать на межі. Побудовано повний топологічний інваріант даних потоків та описано їх топологічну структуру. Обраховано загальну кількість топологічно нееквівалентних потоків на даній поверхні з 4, 6 та 8 особливими точками.
\end{abstract}

\section{1. ВСТуп}

Теорія динамічних систем - популярний розділ математики, який виник як інструмент для дослідження диференціальних рівнянь і стає тепер математичною базою для створення моделей у фізиці, біології, економіці тощо. Потоки Морса-Смейла - один із об'єктів вивчення даної теорії.

Векторне поле, задане на замкненому многовиді, завжди породжуе потік. У випадку компактного многовиду з межею векторне поле буде породжувати потік тоді і тільки тоді, коли воно дотикається до межі в кожній ї̈ точці [1]. На замкнених поверхнях структурно стійкими векторними полями є поля Морса-Смейла. Для многовидів більшої розмірності, крім векторних полів Морса-Смейла, існують інші структурно стійкі векторні поля. Для многовидів з межею аналог полів МорсаСмейла був описаний в роботі [4].

2010 Mathematics Subject Classification: 37C10, 37C15, 37C20

Ключові слова: Поле Морса-Смейла, потік Морса-Смейла, тор з діркою УДК 517.956.4 
Структурна класифікація векторних полів Морса-Смейла на замкнених поверхнях отримана в роботах Пейксото [3], Шарка [7], Персель [2].

Розрізняючий граф для потоків з однією нерухомою точкою на межі поверхні був побудований в [5], а для потоків Морса-Смейла на двовимірному диску в [9].

У даній роботі розглядаються потоки Морса-Смейла на поверхні з межею, а саме на торі з діркою. Аналогічно до потоків на замкнених поверхнях, на поверхнях з межею потоки Морса-Смейла утворюють всюди щільну множину. Серед потоків у яких множина неблукаючих точок складається зі скінченого числа траєкторій структурно стійкими є лише потоки Морса-Смейла [4].

Мета роботи - описати топологічну структуру потоків Морса-Смейла на торі з діркою, у яких особливості лежать на межі поверхні. А також порахувати кількість топологічно нееквівалентних потоків Морса-Смейла на торі з діркою з не більше, ніж 8 особливими точками на межі.

\section{2. ПОТОКИ МОРСА-СМЕЙЛА НА МНОГОВИДІ З МЕЖЕЮ}

Нехай $M$ - гладка поверхня з межею. Ми будемо досліджувати структуру потоків на $M$ з нерухомими точками на межі.

Означення 2.1. Два векторні поля $X_{1}$ і $X_{2}$, задані на замкнених поверхнях $M_{1}$ і $M_{2}$, називаються траекторно еквівалентними, якщо існуе гомеоморфізм $h: M_{1} \rightarrow M_{2}$, який переводить траєкторії векторного поля $X_{1}$ в траєкторії векторного поля $X_{2}$ зі збереженням орієнтації на траєкторіях. Також кажуть, що ці векторні поля мають однакову структуру.

Має сенс розглядати топологічну класифікацію не всіх векторних полів, а тільки структурно стійких векторних полів.

Векторне поле $X$ на многовиді $M$ називається структурно стійким, якщо існує такий окіл $U$ поля $X$ в множині всіх векторних полів на многовиді $M$, що довільне $Y \in U$ є топологічно еквівалентним полю $X$.

Означення 2.2. Векторне поле $X$ на гладкому многовиді $M$ з межею $\partial M$, дотичне до межі, називається полем Морса-Смейла, якщо воно задовольняє таким умовам:

1) множина $\Omega(X)$ неблукаючих точок $X$ складається зі скінченого числа особливих точок та замкнених орбіт, причому всі вони гіперболічні;

2) стійкі та нестійкі многовиди двох елементів з $\Omega(X)$ перетинаються трансверсально на Int M, а якщо для двох таких елементів існує 
точка нетрасверсального перетину на межі, то принаймні один з цих елементів є особливою точкою [8].

Потік, породжений векторним полем Морса-Смейла, будемо називати потоком Морса-Смейла [8].

Означення 2.3. Нерухомі точки потоку Морса-Смейла на межі поверхні будемо поділяти на три типи: стоки, джерела та сідлові точки, причому сідлові точки також розділятимуться на два типи:

- $а$-ciдла - це точки, в які дві траєкторії входять, а одна виходить (при обмеженні потоку на межу вони є стоками);

- b-ciдлa-це точки, в які одна траєкторія входить, а дві виходять (при обмеженні потоку на межу вони є джерелами), [6].

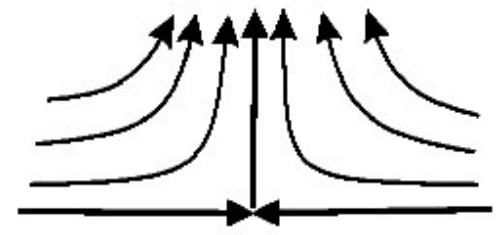

a-сідло

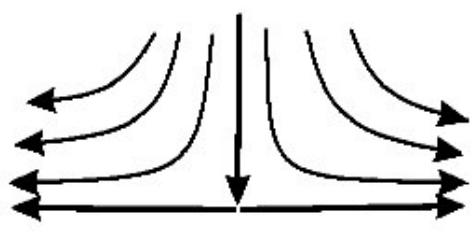

b-сідло

Рис. 2.1. Типи сідлових точок

Сепаратрисами є траєкторії, що починаються або закінчуються у сідлах. Для потоків на поверхні з межею умова 2) в означенні векторного поля Морса-Смейла рівносильна тому, що сепаратриси, які починаються і закінчуються в сідлових точках лежать на межі поверхні.

\section{3. ПОБУДОВА СЕПАРАТРИСНОЇ ДІАГРАМИ}

Нехай $M$ - компактна поверхня з межею, $X$ - векторне поле МорсаСмейла на ній. Якщо розрізати дану поверхню уздовж всіх сепаратрис, то в отриманих областях жодна з траєкторій вже не буде сепаратрисою.

Покажемо, що такі області є однозв'язними. За означенням, регулярні траєкторії (не сепаратриси) починаються у джерелах та закінчуються у стоках. В одній області на межі буде єдиний стік і єдине джерело (якщо це не так, то два стоки або два джерела повинні бути розділені сепаратрисою, що лежить в області, а це суперечить означенню області). Для кожної регулярної кривої з області знайдемо іiї центр (по довжині кривої). Множину центрів відобразимо гомеоморфізмом $h$ на інтервал $(-1,1) \times 0$ на одиничному крузі. Кожну регулярну траєкторію відобразимо лінійним за довжиною дуги гомеоморфізмом на відповідну за гомеоморфізмом $h$ траєкторію векторного поля $\left\{-x y, 1-y^{2}\right\}$ на 
одиничному крузі. Ця топологічна еквівалентність полів є гомеоморфізмом області на внутрішність одиничного круга.

Надалі будемо розглядати потоки Морса-Смейла на торі з діркою 3 нерухомими точками на межі поверхні. Оскільки рід поверхні дорівнює 1, то завжди існуе дві сепаратриси, розрізавши уздовж яких отримаємо однозв'язну область. Це випливає з того, що розрізавши уздовж сепаратриси ми або зменшимо рід (тоді це «перша» шукана сепаратриса), або розіб'ємо поверхню на дві компоненти, одна з яких має рід 1 і тоді на ній продовжимо процедуру, поки не знайдемо «першу» сепаратрису, бо рід областей дорівнює 0. Після розрізання поверхні уздовж першої сепаратриси ми отримаємо поверхню роду 0 з двома компонентами межі (циліндр). Другою сеператрисою буде та, у якої її кінці лежать на різних компонентах межі. Доведення її існування таке саме як для «першої» сепаратриси.

Границя отриманої області гомеоморфна одиничному колу, а сепаратриси (крім тих, уздовж яких ми розрізали) можна розглядати як хорди у цьому колі. На колі маємо 4 виділених дуги, що відповідають двом сепаратрисам, уздовж яких ми розрізали тор з діркою. Причому, пара дуг, що відповідає одній сепаратрисі, задає два протилежно напрямлені напрямки руху граничного кола.

Кожна з цих чотирьох дуг має одним із своїх кінців сідлову точку, а іншим - стік або джерело. Видалимо цю сідлову точку, тобто замінимо пару сусідніх до неї дуг (ребер) однією дугою (ребром), і проробимо це послідовно для кожної з цих чотирьох дуг. При цьому траєкторії нового векторного поля будуть тотожні з попередніми, крім вище зазначених дуг. Після перепараметризації поля отримаємо нове векторне поле на двовимірному диску, яке, за означенням, буде полем Морса-Смейла. Дуги (ребра), отримані після об'єднання будемо називати $a$-ребрами (Рис. 3.1), b-ребрами, а також $a b$-ребрами (Рис. 3.2), в залежності від того, якого типу сідла лежали на них.
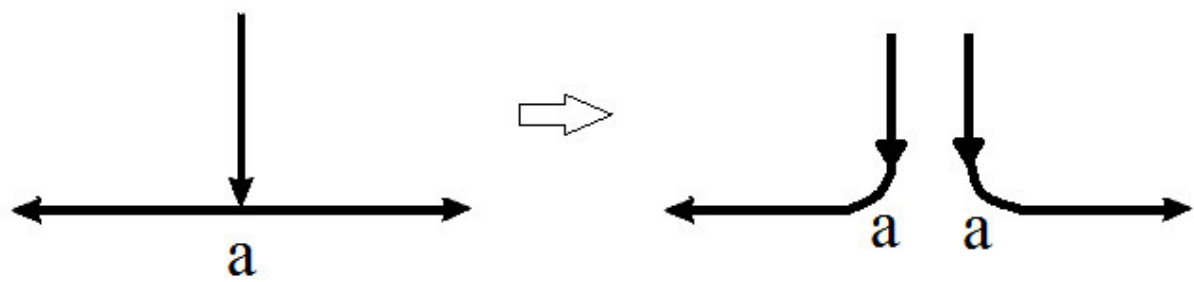

Рис. 3.1. Утворення а-ребра 

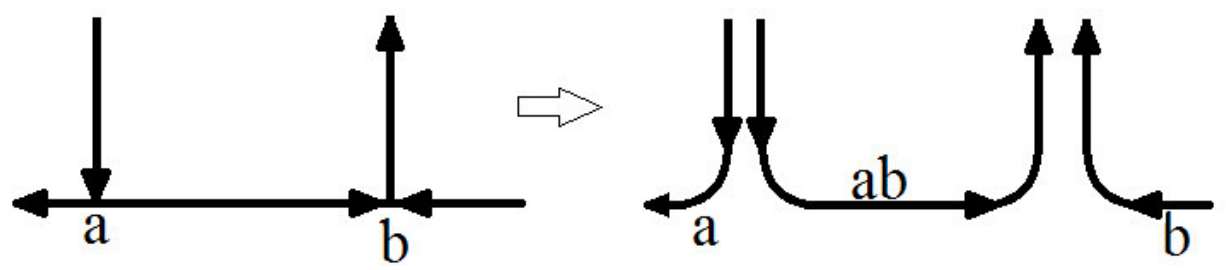

Рис. 3.2. Утворення $a b$-ребра

Означення 3.1. Сепаратрисною діаграмою називається орієнтований граф з виділеним циклом, який проходить через всі вершини по одному разу (даний цикл називатимемо граничним), позначеннями $a, b$ або $a b$ на ребрах. Ребра граничного циклу будемо називати дугами, а інші ребра називатимемо хордами.

Сепаратрисна діаграма, побудову якої за потоком Морса-Смейла описано вище, називається сепаратрисною діаграмою потоку Морса-Смейла.

Лема 3.2. Сепартрисна діаграма потоку Морса-Смейла має такі властивості:

1) Для кожної хорди принаймні один з ї кінців е вершиною валентності 3.

2) Загальне число хорд $l$ та кількість вершин s пов'язані формулою $s=2+2 l$.

3) Кожна хорда розбиває виділений чикл на дві частини (кінці хорди належать кожсній з иих частин) так, що

a) у кожній з частин непарна кількість вершин;

в) для будъ-якої іншої хорди обидва ї̈ кіниі належать одній з двох частин.

4) Якщо деякій з вершин інцидентні більш ніж одна хорда, то всі ці хорди мають по відношенню до вершини напрямок такий, як $i$ іниидентні їи граничні ребра (ия вершина е стоком або джерелом).

5) Після розбиття аь-ребра на два ребра а та b (якщо таке ребро існуе) або в незміненій діаграмі (якщо такого ребра не існуе) буде 4 помічених ребра такі, що протилежні помічені ребра мають однакові позначення а або $b$ i, крім того, задають різні напрямки руху (орієнтачї̈ граничного кола).

Доведення. Оскільки сепаратрисну діаграму можна розглядати як діаграму векторного поля Морса-Смейла заданого на одиничному крузі, то можемо застосувати до неї лему 2.1. із роботи [6]. Тому будуть 
виконуватися всі, крім останньої властивості. Остання властивість рівносильна тому, що після склеювання помічених дуг (тут $a b$-ребра розбиті на два) отримана поверхня буде тором з діркою.

Проілюструємо процес побудови сепаратрисних діаграм при розстановці особливих точок як показано на Рис. 3.3
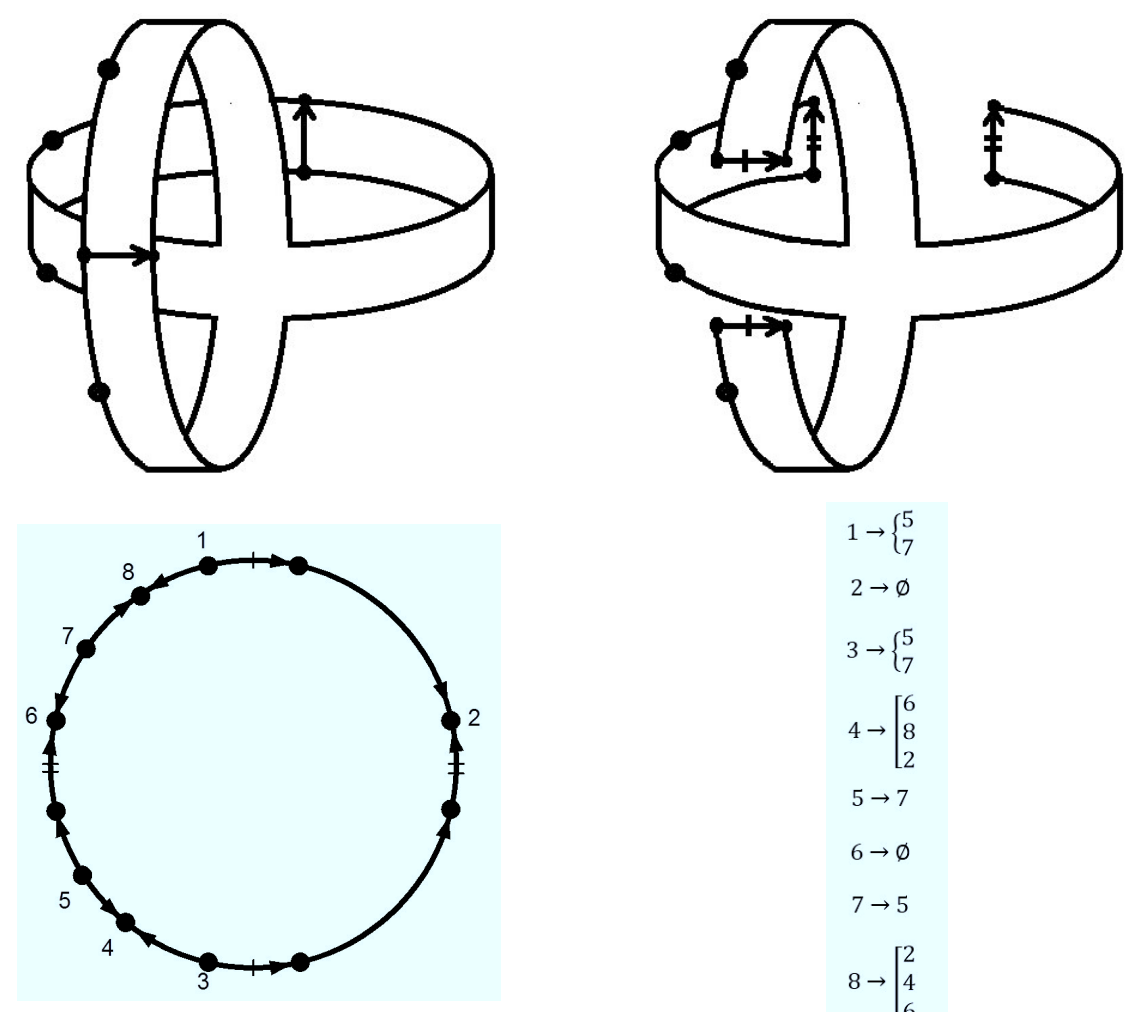

$$
\begin{aligned}
& 1 \rightarrow\left\{\begin{array}{l}
5 \\
7
\end{array}\right. \\
& 2 \rightarrow \varnothing \\
& 3 \rightarrow\left\{\begin{array}{l}
5 \\
7
\end{array}\right. \\
& 4 \rightarrow\left[\begin{array}{l}
6 \\
8 \\
2
\end{array}\right. \\
& 5 \rightarrow 7 \\
& 6 \rightarrow \varnothing \\
& 7 \rightarrow 5 \\
& 8 \rightarrow\left[\begin{array}{l}
2 \\
4 \\
6
\end{array}\right.
\end{aligned}
$$

Рис. 3.3. Один із способів розстановки особливих точок та можливі варіанти проходження сепаратрис

Для кожної із пронумерованих точок визначимо куди може заходити сепаратриса, якщо вона виходитиме з даної точки. Зауважимо, що один із кінців даної сепаратриси повинен бути сідловою точкою, а інший стоком або джерелом. Точка 1 є джерелом, а це означає, що початок сепаратриси також буде джерелом. Для того, щоб її кінець був сідловою точкою, потрібно, щоб вона заходила у джерело (тоді це джерело перетвориться у сідлову точку). Витоки на нашій діаграмі-це точки 3,5 та 7. Але точці 3 не дозволяється бути сідловою, оскільки вона вже є одним із кінців сепаратриси, що лежить на колі (обидва 
кінці сепаратриси одночасно не можуть бути сідловими точками). Отже, з точки 1 можуть виходити сепаратриси в точки 5 та 7 окремо, або одночасно. 3 аналогічних міркувань, з точки 3 можуть виходити сепаратриси також в 5 та 7.

Точка 2 є стоком. Якщо з неї виходитиме сепаратриса, то дана точка перетвориться у сідлову, що неможливо, оскільки вона вже є кінцем сепаратриси. Аналогічні міркування проводяться для точки 6 .

Точка 4 також є стоком. Якщо з неї виходитиме сепаратриса, то вона перетвориться у сідлову точку. Це означає, що один із кінців сепаратриси вже буде сідловою точкою, тобто їі кінцем може бути лише стік. Таким чином, сепаратриса може входити, або в 6, або в 8 , або в 2. Подібними міркуваннями сепаратриси, які виходять із точки 8 , можуть заходити, або в 2, або в 4, або в 6.

Точка 5 - джерело. Для того, щоб кінець сепаратриси був сідловою точкою, потрібно, щоб вона заходила у джерело (тоді дане джерело перетвориться у сідлову точку). Витоки - це точки 1, 3 та 7. Але 1 та 3 не можуть бути сідловими. Отже, залишається лише точка 7. Аналогічними міркуваннями із точки 7 сепаратриса може входити лише в точку 5 .

Перебравши всі можливі варіанти розстановки сепаратрис, отримується набір різних сепаратрисних діаграм. Тут проілюстровано процес побудови сепаратрисних діаграм на прикладі лише одного конкретного способу розстановки особливих точок. Для інших варіантів розстановки особливих точок подібними міркуваннями було знайдено всі можливі сепаратрисні діаграми (детальніше в розділі 5).

\section{4. ТОПОЛОГІЧНА ЕКВІВАЛЕНТНІСТЬ ПОТОКІВ}

Відмітимо, що сепаратрисна діаграма залежить від вибору пари сепаратрис уздовж яких ми розрізаємо тор. Тому різні вибори пар сепаратрис можуть задавати різні сепаратрисні діаграми. Покажемо, що сепаратрисні діаграми, побудовані за одним і тим же потоком МорсаСмейла, можна отримати одну з одної за допомогою певного процесу перебудови.

Кожну діаграму розрізаємо уздовж їі внутрішніх сепаратрис. Отримані криволінійні многокутники склеюємо уздовж пар відповідних дуг, які лежали на колі, і утворений новий криволінійний многокутник знову розглядаємо як сепаратрисну діаграму (Рис. 4.1-4.4). Для кожної сепаратрисної діаграми існує декілька способів її перебудови.

Означення 4.1. Дві сепаратрисні діаграми будемо вважати однаковими, якщо одну із них можна отримати з іншої за допомогою симетрії 


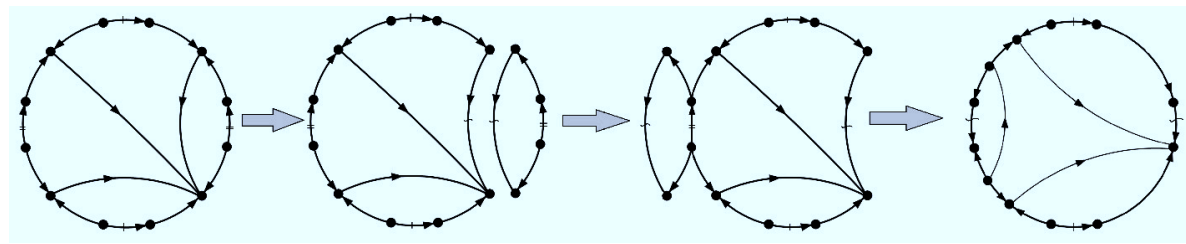

Рис. 4.1. Розрізання уздовж правої сепаратриси та склейка уздовж бічних дуг

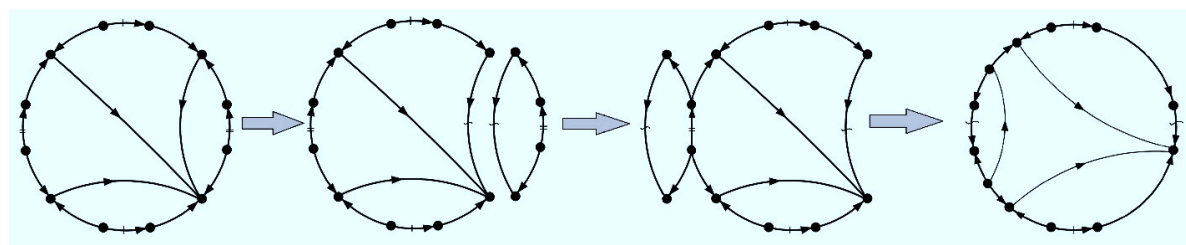

Рис. 4.2. Розрізання уздовж середньої сепаратриси та склейка уздовж бічних дуг

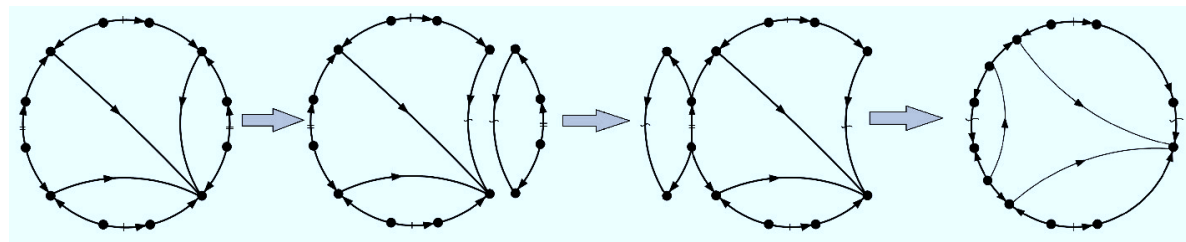

Рис. 4.3. Розрізання по середній сепаратрисі та склейка уздовж верхньої та нижньої дуг

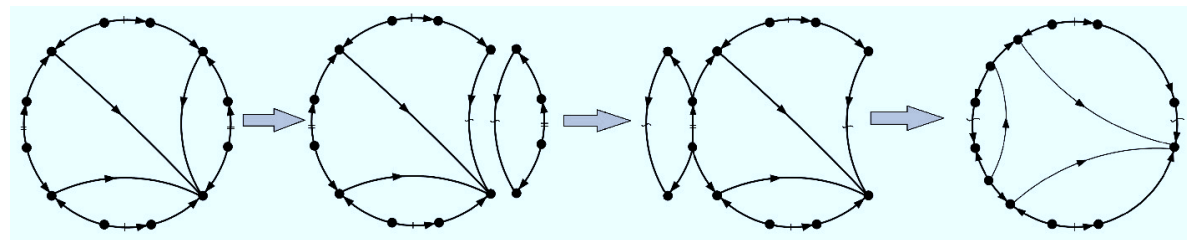

Рис. 4.4. Розрізання по нижній сепаратрисі та склейка уздовж верхньої та нижньої дуг

або повороту, та еквівалентними, якщо одна із них отримується з іншої за допомогою процесу перебудови сепаратрисних діаграм. 
Теорема 4.2. Два потоки Морса-Смейла на торі з діркою є топологічно еквівалентними тод $i$ тільки тоді, коли $\ddot{x}$ сепаратрисні діаграми $\epsilon$ еквівалентними.

Доведення. Необхідність випливає з побудови: якщо два потоки $X$ та $Y$ топологічно еквівалентні, то існує гомеоморфізм, який відображає траєкторії в траєкторії, сепаратриси в сепаратриси, а області в області. Тоді еквівалентність сепаратрисних діаграм випливає з процесу їх побудови.

Достатність. Якщо дві сепаратрисні діаграми еквівалентні, то розрізавши кожну з них уздовж сепаратрис (хорд) отримаємо криволнійні многокутники, сторони яких (сепаратриси) склеєні між собою. Еквівалентність сепаратрисних діаграм рівносильна тому, що між множинами криволінійних многокутників існує бієкція і для відповідних многокутників існує гомеоморфізм, який узгоджений з гомеоморфізмами сторін, що склеюються. Змінимо гомеоморфізми всередині цих многокутників таким чином, щоб траєкторії відображались на траєкторії. Це дасть шукану топологічну еквівалентість векторних полів.

Теорема 4.3. Якщо сепаратрисна діаграма має властивості 1)-5) 3 леми 3.2, то вона е сепаратрисною діаграмою деякого потоку МорсаСмейла заданого на торі з діркою.

Доведення. Якщо сепаратрисна діаграма має властивості 1)-4), то вона задає потік Морса-Смейла на двовимірному диску, [6]. На відмічених дугах цього потоку виберемо довільно по одній точці для $a$ - та $b$ ребер та дві точки для $a b$-ребра. Розіб'ємо дуги цими точками та виділимо дуги відповідно до типу точок (процедура обернена до об'єднання дуг при побудові сепаратрисної діаграми). За властивістю 5) маємо 4 виділені дуги, склеївши які за гомеоморфізмами відповідно напрямків руху, отримаємо тор з діркою. Після заміни векторного поля швидкостей у околах склеєних вершин на поле Морса-Смейла у околах $a$ - та b-сідел, отримаємо шукане векторне поле.

\section{5. ЗНАХОДЖЕННЯ ЗАГАЛЬНОЇ КІЛЬКОСТІ ПОТОКІВ МОРСА-СМЕЙЛА}

Для випадку 4-х особливих точок, розставлених на межі тора з діркою, не знайдено жодного потоку Морса-Смейла, адже з Рис. 5.1 видно, що у даній області присутні два стоки та два джерела, що забороняється. Внутрішні сепаратриси провести неможливо.

Для випадку 6 особливих точок, розставлених на межі даної поверхні, було отримано 8 сепаратрисних діаграм, а для випадку з 8 особливими точками - 106 сепаратрисних діаграм. 


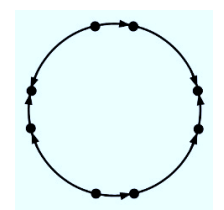

Рис. 5.1. Сепаратрисна діаграма потоку з 4 особливими точками

Кожну із отриманих діаграм було перебудовано всіма можливими способами, в результаті чого було виявлено, що велика кількість діаграм є еквівалентними Для випадку 6 особливих точок було виявлено 2 класи еквівалентності, див Рис. 5.2.
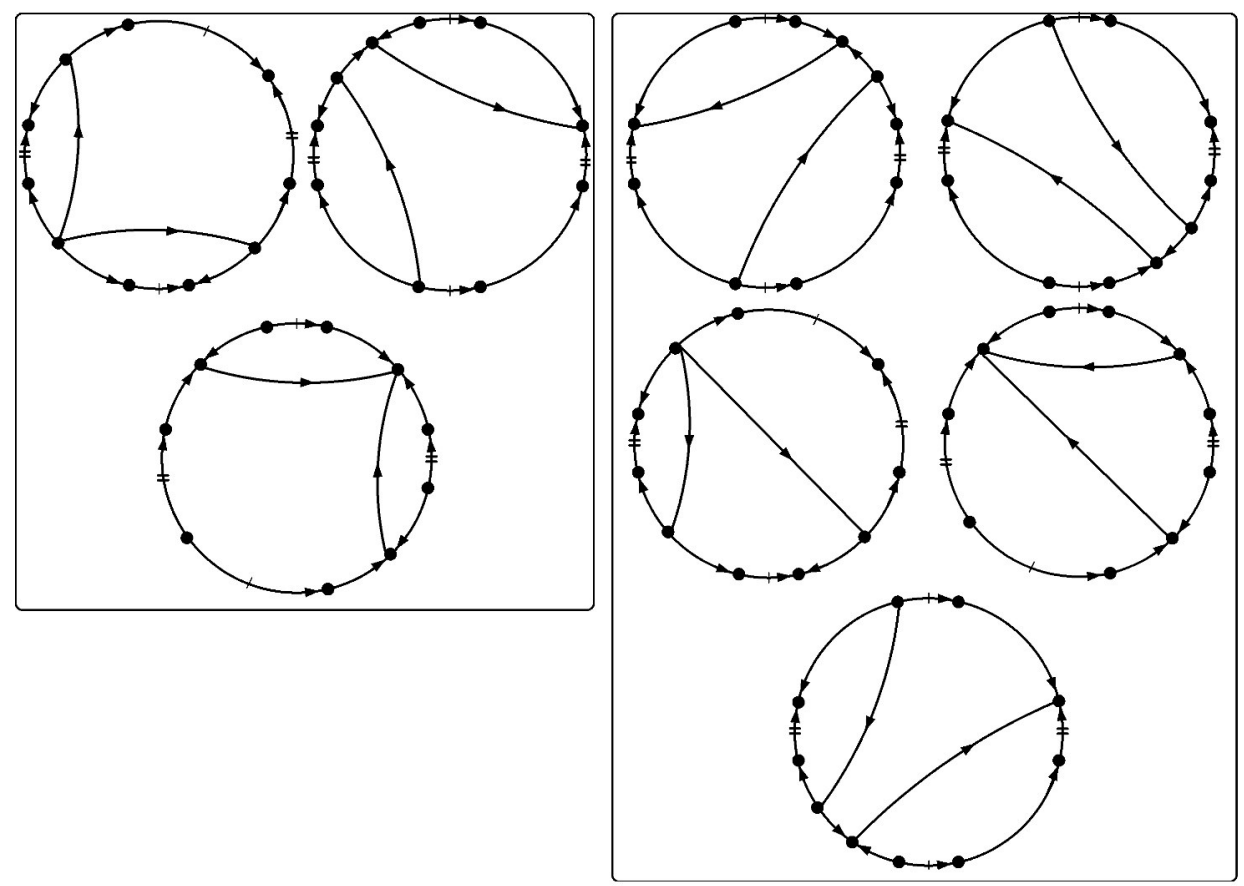

Рис. 5.2. Перший та другий класи еквівалентних сепаратрисних діаграм

Для випадку 8 особливих точок було отримано 18 класів еквівалентності, по одному із представників яких зображено на Рис. 5.3.

\section{6. Висновки}

В даній роботі побудовано повний топологічний інваріант для потоків Морса-Смейла на торі з діркою, у яких всі особливі точки лежать 

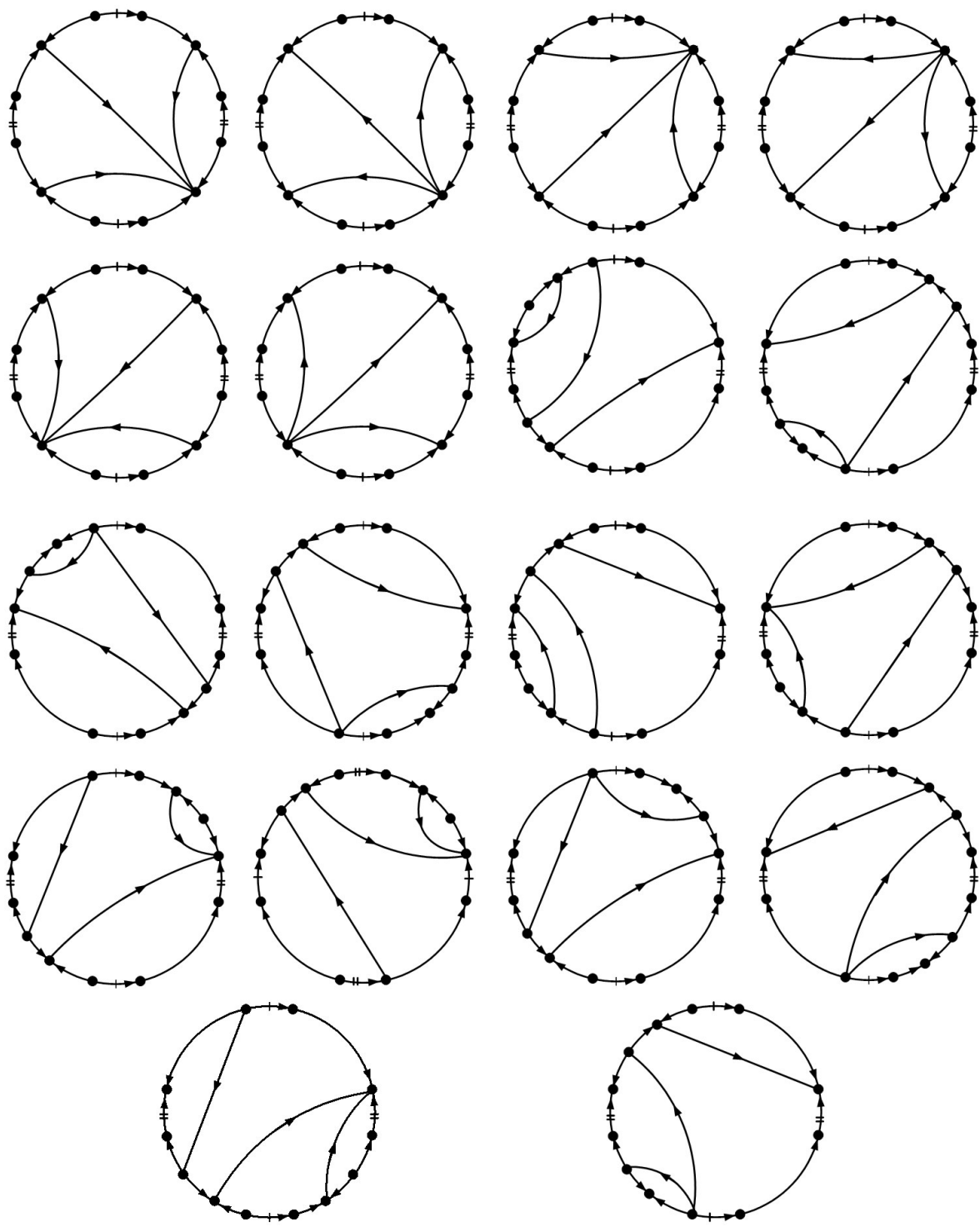

Рис. 5.3. Представники 18 класів еквівалентності

на межі. Отримано топологічну класифікацію таких потоків та описано їх топологічну структуру з не більше, ніж 8 особливими точками. Отриманий підхід до топологічної класифікації таких потоків може бути використаний як для орієнтованих поверхонь більшого роду, так i 
для неорієнтованих поверхонь. Автори сподіваються, що вдасться узагальнити отримані результати для цих випадків.

\section{ЛIтЕРАТУРA}

[1] G. Fleitas. Classification of gradient-like flows on dimensions two and three. Boletim da Sociedade Brasileira de Matemática, 6(2):155-183, 1975.

[2] M. M. Peixoto. Structural stability on two-dimensional manifolds. Topology, 1:101-120, 1962.

[3] Peter B. Percell. Structural stability on manifolds with boundary. Topology, 12:123-144, 1973.

[4] Clark Robinson. Structural stability on manifolds with boundary. Journal of Differential Equations, 37(1):1-11, 1980.

[5] М. В. Лосєва, О. О. Пришляк. Топологія 1-потоків на поверхнях з межею. In Abstracts of international conference «Geometry and Topology in Odessa - 2016», page 50, 2016.

[6] М. В. Лосєва, О. О. Пришляк. Топологія потоків Морса-Смейла з особливостями на межі двовимірного диска. Proceedings of the International Geometry Center, 9(2):3241, 2016.

[7] А. А. Ошемков, В. В. Шарко. О классификации потоков Морса-Смейла на двумерных многообразиях. Матем. сборник, 189(8):93-140, 1998.

[8] О. О. Пришляк. Топологія многовидів. КНУ імені Тараса Шевченка, 2015.

[9] О. О. Пришляк. Топологія потоків на поверхнях з межею. In Abstracts of 11-th summer school «Algebra, Topology, Analysis», 2016.

Надійшла до редакиї 9 січня 2017, прийнята до друку 11 березня 2017.

Пришляк Олександр Олегович

КИЇВСЬКИЙ НАЦІОНАЛЬНИЙ УНІВЕРСИТЕТ ІМЕНІ ТАРАСА ШЕВЧЕНКА, ВУЛ. ВОЛОДИмИРСЬКА, 64, м. КИїв, 01601, УкРАїнА

Email: prishlyak@yahoo.com

ORCID: orcid.org/orcid.org/0000-0002-7164-807X

Прус Андрій Анатолійович

КИЇВСЬКИЙ НАЦІОНАЛЬНИЙ УНІВЕРСИТЕТ ІМЕНІ ТАРАСА ШЕВЧЕНКА, ВУЛ. ВОЛОДИмИРСЬКА, 64, м. КИїв, 01601, УКРАїнА

Email: andrei.prus@mail.ru 